E3S Web of Conferences 1, 31004 (2013)

DOI: $10.1051 / \mathrm{e} 3$ sconf/20130131004

(C) Owned by the authors, published by EDP Sciences, 2013

\title{
Hydrometallurgical Processing and Recovery of Nickel from Spent Cathode Ray Tubes
}

\author{
V. Coman ${ }^{1}$, B. Robotin ${ }^{1}$ and P. Ilea ${ }^{1}$ \\ ${ }^{1}$ Babes-Bolyai University, Faculty of Chemistry and Chemical Engineering, 11 Arany Janos Street, RO-400028 Cluj- \\ Napoca, Romania,vcoman@chem.ubbcluj.ro, biordache@chem.ubbcluj.ro,pilea@chem.ubbcluj.ro
}

\begin{abstract}
Scientific and technological progress required for more and more advanced electrical and electronic equipment (EEE). Therefore, EEE manufacturing became one of the most important world activities, generating at the same time huge amounts of waste. In the last decades the accumulation of waste electrical and electronic equipment (WEEE) has become a global problem (Widmer et al., 2005; Babu et al., 2007; Robinson, 2009). These wastes are a threat for the environment due to their high content of toxic materials and, at the same time, they are an important source of recyclable materials, and especially valuable metals (e.g. Au, Ag, $\mathrm{Pd}, \mathrm{Cu}, \mathrm{Ni}, \mathrm{Zn}$ ). Nowadays there are various approaches for the treatment and recycling of WEEE, involving pyro-, hydro- and bio-metallurgical processes (Cui and Zhang, 2008). Among WEEE, cathode ray tubes (CRT) displays, used mainly in computer monitors and television sets, are regarded as the most polluting fraction of all WEEE (Nnorom et al., 2011). CRT recycling represents a challenge due to their high accumulation rate, proportional to the evolution of modern technologies (flat panel displays), their high content of toxic and noxious substances (heavy metals and organic compounds), improper storage, and the lack of a complete, pollution-free recycling solution. Previous studies have shown that some CRT metallic components (electron gun - EG, shadow mask) contain important amounts of $\mathrm{Ni}(25-45 \%)$ and $\mathrm{Fe}(50-70 \%)$, and small quantities of $\mathrm{Mn}$, Co and Cr (Robotin et al., 2011). Ni and Ni alloys play an important role in modern technology, especially due to their magnetic and anticorrosion properties. Unfortunately, when exposed inappropriately, Ni can have negative environmental effects and can be harmful to human health (Denkhaus and Salnikow, 2002). In this context, Ni recycling from electronic waste is important for environmental and health reasons, and, at the same time, Ni recycling could be financially sustainable due to an elevated Ni market price. In the current study we propose a technological process for Ni recovery from the metallic components of CRT waste. After a preliminary separation into glass, plastic, ceramic and metallic parts, the metallic components were subjected to a magnetic separation and their composition was determined. We have chosen to recover Ni from the magnetic components due to a higher content of $\mathrm{Ni}$ and to avoid the contamination with $\mathrm{Cr}$ (present in the nonmagnetic components). In the next step, chemical and electrochemical waste solubilisation was performed (Robotin et al., 2011). Apart from Ni (25-36 \%), the resulting solutions contain large amounts of Fe (50-64 \%) and small quantities of $\mathrm{Co}$ and $\mathrm{Mn}$. In order to obtain metallic $\mathrm{Ni}$, the solution needed to be purified, the first step being Fe removal. Fe was separated by chemical precipitation of $\mathrm{Fe} 3+$ under $\mathrm{pH}$ and temperature control. $\mathrm{Ni}$ was deposited on copper electrodes by electrowinning. At the same time, the electrodeposition of $\mathrm{Ni}-\mathrm{Fe}$ alloys from synthetic solutions similar to those obtained by dissolution of EG waste was studied. The influence of some parameters (current density, bath composition, $\mathrm{Ni} 2+\mathrm{Fe} 2+$ ratio) on the electrodeposition process was investigated.
\end{abstract}




\section{References}

Babu BR, Parande AK, Basha CA. Electrical and electronic waste: A global environmental problem. Waste Manage Res. 2007;25:307-18.

Cui J, Zhang L. Metallurgical recovery of metals from electronic waste: A review. J Hazard Mater. 2008;158:228-56.

Denkhaus E, Salnikow K. Nickel essentiality, toxicity, and carcinogenicity. $\mathrm{Cr}$ Rev Oncol-Hem. 2002;42:35-56.
Nnorom IC, Osibanjo O, Ogwuegbu MOC. Global disposal strategies for waste cathode ray tubes. Resour Conserv Recy. 2011;55:275-90.

Robinson BH. E-waste: An assessment of global production and environmental impacts. Sci Total Environ. 2009;408:183-91.

Robotin B, Coman V, Ilea P. Nickel recovery from electronic waste i. Nickel recovery from cathode ray tubes. Stud Univ Babes-Bol Chem. 2011:121-30.

Widmer R, Oswald-Krapf H, Sinha-Khetriwal D, Schnellmann M, Böni H. Global perspectives on ewaste. Environ Impact Asses. 2005;25:436-58. 